\title{
The frontal-impact response of a booster-seated child-size PMHS
}

\author{
Francisco J. Lopez-Valdes, Jason Forman, Joseph Ash, Matt Kindig, John Lamp, \\ Richard Kent \\ University of Virginia, Center for Applied Biomechanics \\ Katarina Bohman, Ola Bostrom \\ Autoliv Research
}

\begin{abstract}
This paper presents the response of a child-size Post Mortem Human Subject in a series of frontal impact sled tests. Specific focus is on the whole-body kinematics and resulting head trajectories under two different restraint conditions (booster seat and standard belt, booster seat and force-limiting pre-tensioning belt) in a rear seat environment. At $48 \mathrm{~km} / \mathrm{h}$, the pretensioning, force-limiting seatbelt reduced the forward excursion of both the head $(353 \mathrm{~mm}$ vs. $424 \mathrm{~mm})$ and the h-point $(120 \mathrm{~mm}$ vs. $152 \mathrm{~mm})$ compared to the standard system. Maximum torso pitch was similar for both seatbelts. There were no apparent adverse effects of the force-limiting or pretensioning for the limited sets of conditions considered here
\end{abstract}

Keywords: Frontal impact, child restraint systems, kinematics, restraint systems.

TRAUMATIC BRAIN and skull injuries are the most common serious injuries sustained by children in motor vehicle crashes regardless of age group, crash direction or restraint type (Arbogast et al., 2004; Arbogast et al., 2002; Sherwood et al., 2003). Head injuries are responsible for one-third of all pediatric injury deaths (Adekoya et al., 2002; Thompson and Irby, 2003). These head injuries can be caused by inertial loading of the head or by direct contact with any hard structure of the interior of the car (Arbogast et al., 2002). In either case, the correct description of the kinematics of a child in a frontal impact is key to understand injury causation and therefore to prevent injuries.

NHTSA recommends that children age 12 and under sit in the rear seat (NHTSA, 2007). Approximately $69 \%$ of all rear seat passengers are 14 years old or younger (Kent et al., 2007). In this scenario, the potential for head contact with the interior of the car (for instance, with the rear surface of the front seat) must be assessed.

In the United States, the Federal Standard FMVSS No. 213 specifies requirements for child restraint systems (CRS), including limits on HIC and head excursion. In Europe, regulation ECE No. 44 sets head excursion limits for CRS and the New Car Assessment Program (EuroNCAP) performs an evaluation of different CRS with consideration of the head excursion in a frontal impact, among other parameters.

As an ongoing research program, the University of Virginia is evaluating different restraint systems in the rear seat. Standard seatbelts as well as pre-tensioning, force-limiting seatbelts have been tested using different occupant sizes and ages. Though the rear seat has been traditionally the safest location for an occupant (Smith and Cummings, 2004), some recent studies have shown that the relative safety of the rear seat compared to the front may be declining. Studies have found older occupants to be at a higher risk when they are seated in the rear seat compared to the front seat (Kuppa et al., 2005 and Kent et al., 2007) suggest that the effectiveness of the rear seat for preventing fatalities and serious injuries (compared to the frontal passenger seat) has decreased over the years. Potential explanations for that decrease include the trend toward stiffer frontal structures in newer cars with the concomitant implementation of pre-tensioners and force-limiting seatbelts $(\mathrm{PT}+\mathrm{FL})$ in the front seats and not in the rear.

Future efforts to enhance occupant protection and restraint performance in the rear seat will require biomechanical data on the response of humans in that environment. Of particular 
importance is prospective, well-documented laboratory data on the kinematics of smaller occupants (children) during frontal impacts. The scarcity of biological models of the human child is a challenge in this regard. This study presents the results of a series of 3 frontal sled tests using a post mortem human surrogate (PMHS) that, while of adult age, is the size of a child. Repeated impacts were performed in order to maximize the information gleaned from this rare test subject. Two different speeds and two restraint systems were considered in a test matrix designed to minimize tissue changes due to repeated testing (Table 1). The objective of this paper is to report the sled test findings and to make a preliminary assessment of the potential benefits of using an advanced restraint system in the rear seat with a booster seated, biological model of the human child.

\section{METHODS}

\section{EXPERIMENTAL SETUP}

A total of 3 sled tests was performed on a small PMHS (Table 2) having approximately the anthropometry of a 10 year old child (Table 3 ). The occupant was positioned in a low-back booster seat (Model Step 3 Turbobooster, Graco) on the passenger side of the rear seat in a buck designed to represent a 2004 model year mid-sized U.S. sedan (Fig. 1). The acceleration pulses were approximately trapezoidal in shape (Fig. 2) and were chosen to represent the deceleration of a mid-sized U.S. sedan in a full frontal barrier test (Forman et al., 2006). Two seatbelt systems were considered: a progressive load limiting (nominal $3-\mathrm{kN}$ and $5-\mathrm{kN}$ limits, see Forman et al. 2008 for additional detail), pre-tensioned belt (FL+PT) and a standard (not force-limited or pretensioned) belt (SB). The seatbelt retractors were mounted on the rear deck of the buck (i.e., no D-ring was used). The entire seatbelt system and the seat cushion were replaced after each test. The initial position of the head and the hands was maintained before impact using pre-cut breakable tape that allowed the body to move freely at the initiation of sled deceleration.

Table 1. Text Matrix

\begin{tabular}{|c|c|c|c|}
\hline Test Number & Seating Location & Restraint & Impact speed $(\mathrm{km} / \mathrm{h})$ \\
\hline 1384 & Rear Seat - Passenger & FL+PT + Booster & 28.9 \\
\hline 1385 & Rear Seat - Passenger & FL+PT + Booster & 48.5 \\
\hline 1388 & Rear Seat - Passenger & SB + Booster & 49.6 \\
\hline
\end{tabular}

\section{PMHS PREPARATION}

The PMHS was screened for HIV, hepatitis B and C, and pre-existing injury or bone pathology prior to inclusion in the study. The subject presented a degenerative burst fracture of the T7 vertebral body prior to testing but no other significant bone pathology. The unembalmed PMHS was preserved by freezing. It was thawed at room temperature for 72 hours prior to instrument installation and test preparation. The PMHS was prepared the day before the first test and was kept in a cooler at $40^{\circ}$ Fahrenheit between tests. During the impact, both the pulmonary and cardiovascular systems were pressurized to a nominal in vivo level (approximately $10 \mathrm{kPa}$ measured externally). The pressure was maintained using an onboard pressurization system. The test and handling procedures were approved by the University of Virginia Center for Applied Biomechanics Oversight Committee.

\section{INSTRUMENTATION}

The PMHS was instrumented to measure triaxial acceleration (Endevco model 7264B) and triaxial angular velocity (DTS model ARS-12k) at the head and the first thoracic vertebra (T1). Triaxial acceleration was measured at the middle of the thoracic spine (T9), at the lumbar spine (L2), and at the pelvis. Also a uniaxial accelerometer was installed on the sternum. Accelerometers were rigidly attached to bony structures by specifically designed mounts. 

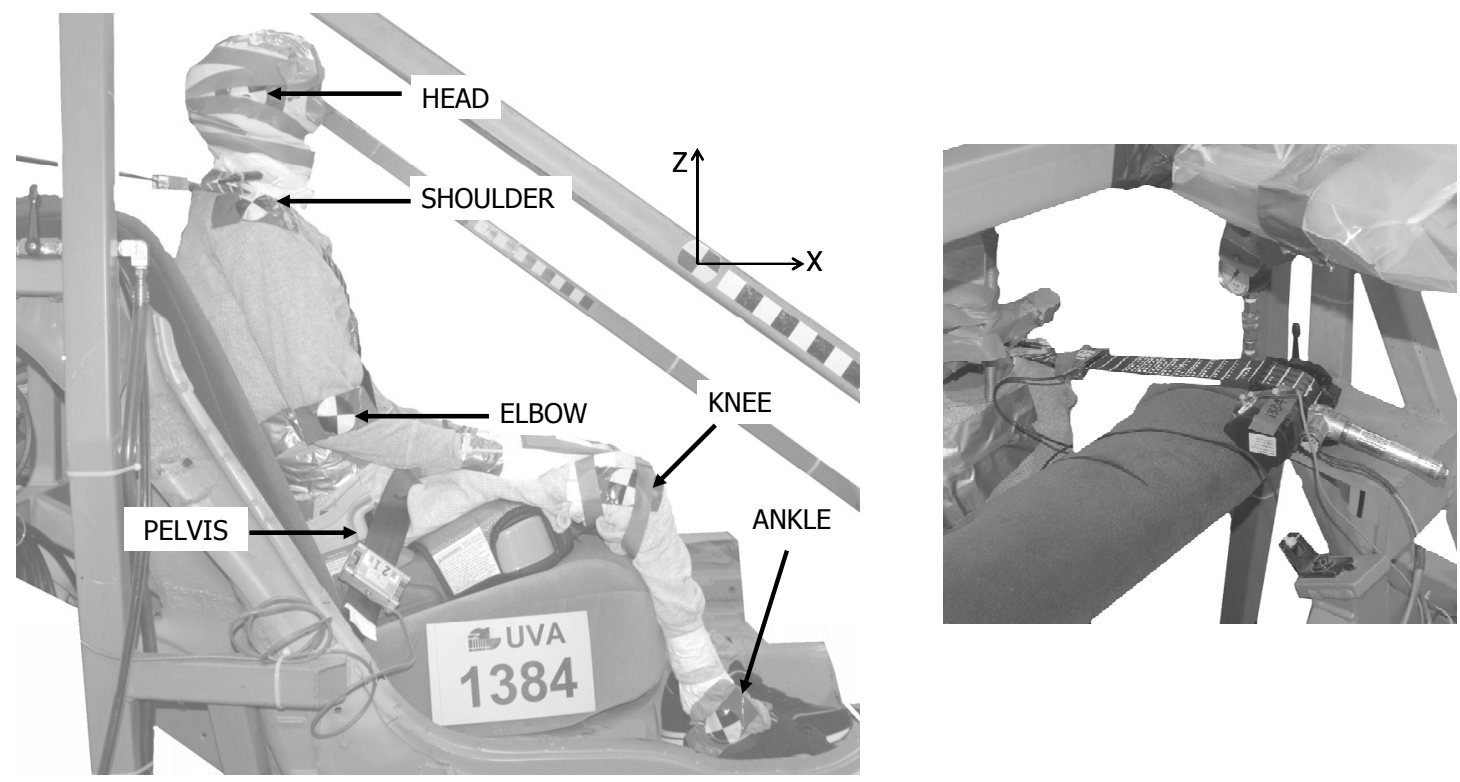

Fig. 1 - Left: Position of the PMHS in the buck. Reference system and points tracked during the impact. Torso angle is defined between the vector that joins the pelvis to the shoulder and a vector pointing in the $X$ direction. Right: detail of the retractor.

Pressure at the aorta and trachea was also measured. All acceleration and angular velocities were measured in a local xyz reference frame that translated and rotated with the associated occupant body segment. Tension on the seatbelt was measured (Eaton Lebow, Model Number 3419-3.5K) at the upper (between the shoulder and the retractor) and lower (above the buckle) shoulder belt and at the outboard lap belt. Two chest band instruments were utilized to measure chest deformation and cross-sectional thorax shape. These instruments consist of a flexible band with strain gauge bridges wrapped tightly around the thorax at the nominal levels of the $4^{\text {th }}$ and $8^{\text {th }}$ ribs.

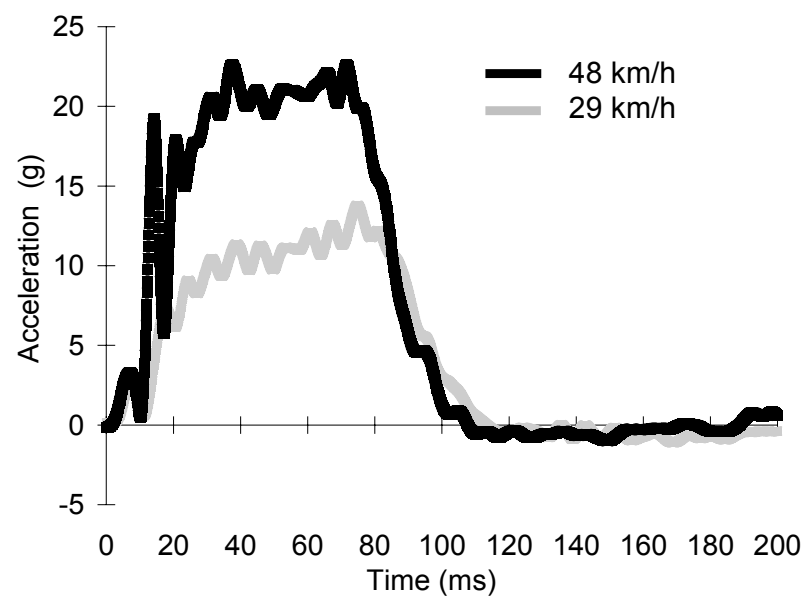

Table 2. PMHS information

\begin{tabular}{|c|c|}
\hline $\begin{array}{c}\text { Cadaver ID No. } \\
\text { death }\end{array}$ & 437 \\
\hline Sex & Female \\
\hline Cause of death & $\begin{array}{c}\text { Lung } \\
\text { cancer }\end{array}$ \\
\hline $\begin{array}{c}\text { Preservation } \\
\text { method }\end{array}$ & Freezing \\
\hline Body mass (kg) & 27.2 \\
\hline Stature $(\mathrm{cm})$ & 147.0 \\
\hline
\end{tabular}

Fig. 2 - Sled deceleration pulses.

\section{DATA ANALYSIS}

\section{Occupant kinematics}

Each test was recorded with two (driver and passenger side) off-board digital high speed cameras at 1000 frames per second. Trajectories were determined in the buck reference frame (XZ) from the passenger-side images for the head, shoulder, hip, knee and ankle and for the CRS and the buck (see Fig. 1). Occupant trajectories relative to the vehicle interior were determined by subtracting the buck displacement from the X-axis displacement of each body point. Head photo targets were placed at points approximately lateral to the head center of 
gravity. Shoulder targets were superficial to the acromion process. Hip photo targets were placed superficially to the $\mathrm{H}$ point (greater trochanter, nominally the hip center of rotation). Knee targets were superficial to the nominal knee center of rotation. Ankle photo targets where placed superficial to the lateral malleolus. Photo targets were attached to the skin with surgical staples. Torso angle was calculated as illustrated in Fig. 1. The trajectories of the photo targets were digitized manually using commercial analysis software (Phantom Camera Control version 8.1.607, Vision Research, Inc.).

Table 3. Subject anthropometry (mm)

\begin{tabular}{|c|c|c|c|}
\hline Stature & 1470 & Buttock Depth & 157 \\
\hline Vertex-to-Symphision Length & 800 & Shoulder-to-Elbow & 280 \\
\hline Top-of-Head to Trochanterion & 755 & Forearm-to-Hand & 370 \\
\hline Shoulder (Acromial) Height & 1295 & Tibiale Height & 340 \\
\hline Waist Height (at Umbilicus) & 945 & Ankle Height (Outside) & 75 \\
\hline Waist Depth (at umbilicus) & 145 & Foot Breadth & 65 \\
\hline Waist Breadth & 233 & Foot Length & 210 \\
\hline Shoulder Breadth (Biacromial) & 320 & Head Length & 205 \\
\hline Chest Breadth $-4^{\text {th }}$ Rib & 234 & Head Breadth & 130 \\
\hline Chest Breadth $-8^{\text {th }}$ Rib & 240 & Head Height & 190 \\
\hline Chest Depth $-4^{\text {th }}$ Rib & 175 & Head Circumference & 517 \\
\hline Chest Depth $-8^{\text {th }}$ Rib & 140 & Neck Circumference & 255 \\
\hline Waist Circumference (umbilicus) & 555 & Chest Circumference $-4^{\text {th }}$ Rib & 710 \\
\hline Hip Breadth & 270 & Chest Circumference $-8^{\text {th }}$ Rib & 640 \\
\hline
\end{tabular}

\section{Sensor data}

All sensors were recorded at $10 \mathrm{kHz}$ and filtered according to the Society of Automotive Engineers J211 recommendations (1988). NHTSA's RBandPC software (RBANDPC and DEFLECT v.3.0, 2001) was utilized to produce chest band contours at selected time intervals throughout the impact event. Head acceleration was measured as part of a 6-degree-offreedom cube (triaxial linear acceleration and triaxial angular rate) mounted at an arbitrary location on the head.

\section{RESULTS}

Images from the off board passenger side camera are presented in Fig. 8. The trajectories of the head, shoulder, hip, knee, elbow, and ankle with respect to the buck reference frame are shown in Fig. 3. In the lower-speed test, the head c.g. traced a circular path around the shoulder with relatively little forward displacement relative to the buck $(186 \mathrm{~mm})$. In the high speed impacts, the forward excursion of the shoulder is less with the FL+PT system than with the SB system (Fig. 3). There is also less forward excursion of the hip (120 mm in Test 1385 compared to $152 \mathrm{~mm}$ in Test 1388). The net effect of this decrease in hip and shoulder excursion is a substantial reduction in forward head excursion for the FL+PT system compared to the SB system (353 mm vs. $424 \mathrm{~mm}$ ). Furthermore, the nature of the head trajectorial path is different. With the SB system, the head translates forward relative to the buck and actually moves slightly upward before beginning its downward arc after approximately $215 \mathrm{~mm}$ of forward excursion. In contrast, the FL+PT system initiated a downward arc immediately. The nature of the shoulder path also differed slightly between the two restraints. With the SB the shoulder trajectory was nearly straight forward. With the FL+PT system the shoulder exhibited a concave-up trajectory with an initial path forward and downward followed by a forward trajectory upward. This is a result of the earlier engagement of the pretensioned shoulder belt, which can also be seen in the force measurements presented in Fig. 6. Pelvis maximum forward excursion was $89 \mathrm{~mm}$ in Test 1384. The FL+PT belt reduced the maximum pelvis excursion from $152 \mathrm{~mm}$ in Test 1388 to $121 \mathrm{~mm}$ in Test 1385 , resulting in a more controlled displacement of the pelvis. 


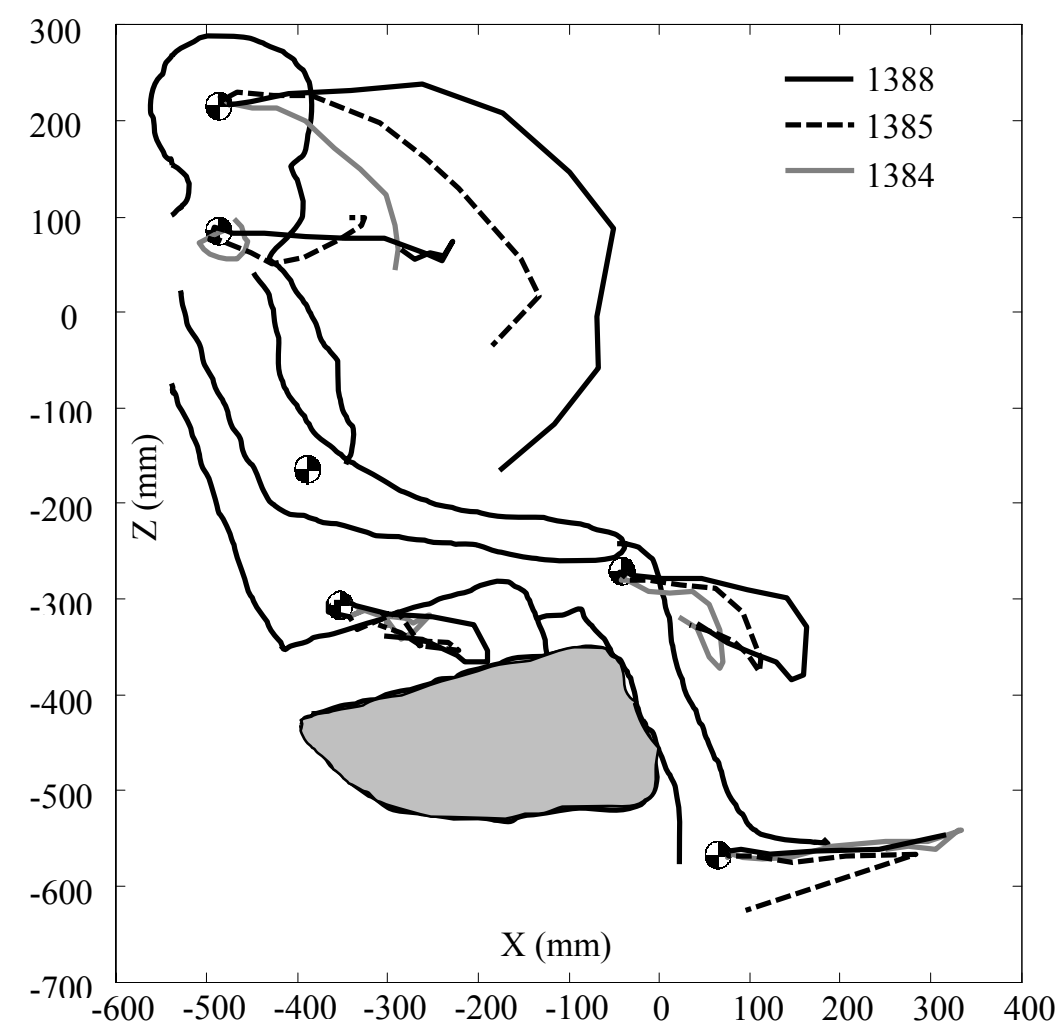

Fig. 3 - Trajectories of body segments with respect to the buck reference in the different tests. Test 1384 was used as reference.

Torso angle was calculated from the trajectory data of the shoulder and the pelvis and the change of this angle over time is shown in Fig. 4. Torso pitch angle was found to range from $110^{\circ}$ at the beginning of the impact to $104^{\circ}$ at $\mathrm{t}=200 \mathrm{~ms}$ in the $29 \mathrm{~km} / \mathrm{h}$ test and $84^{\circ}$ at $\mathrm{t}=180$ $\mathrm{ms}$ in both $48 \mathrm{~km} / \mathrm{h}$ tests. Though the total torso rotation was similar with the two restraints in the $48 \mathrm{~km} / \mathrm{h}$ tests, the time histories of the pitch angle were substantially different. With the FL+PT system, the forward pitch was delayed relative to the SB system due to the shoulder-belt pretensioner stroke, but then increased at a greater rate as the belt force was limited. The net effect was a bi-model torso angle-time history for the FL+PT system and a monotonic history for the SB. The high-speed images in Fig. 8 illustrate additional effects of the FL+PT system. As a result of the SB system's later engagement of the shoulder, the torso is able to build more velocity relative to the buck before significant restraining forces are applied. The result is a pronounced and distributed lordotic curvature of the spine as the belt force peaks with the SB system (see the 80-ms images in Fig. 8, in particular the shoulder position in test 1388 compared to 1385). This is less pronounced with the FL+PT system, presumably due to both aspects of the system. The pre-tensioner engages the torso earlier and reduces the rate at which the torso's velocity builds while the force-limiter mitigates the amount of force applied to the shoulder and hence reduces the induced lordosis when belt force is applied to the shoulder.

The time history of the lower and upper seatbelt tension are presented in Fig. 5 and Fig. 6 The highest belt tensions were measured in the high-speed test with the SB system (peak of $4528 \mathrm{~N}$ at the upper shoulder belt and $2730 \mathrm{~N}$ at the lower shoulder belt). The time of the peak tension at both locations in the SB system (upper and lower shoulder) was similar (78.1 $\mathrm{ms}$ and $79.2 \mathrm{~ms}$ ). In both tests with the FL+PT system, the peak tension at the upper location lags the peak at the lower location (Fig. 4) despite the use of a shoulder pretensioner. The peak upper shoulder tension in the FL+PT belt was $3035 \mathrm{~N}$ at $48 \mathrm{~km} / \mathrm{h}$ and $2203 \mathrm{~N}$ at 29 $\mathrm{km} / \mathrm{h}$. It is apparent from the tension time histories that the belt force limiter yielded at both test speeds. 


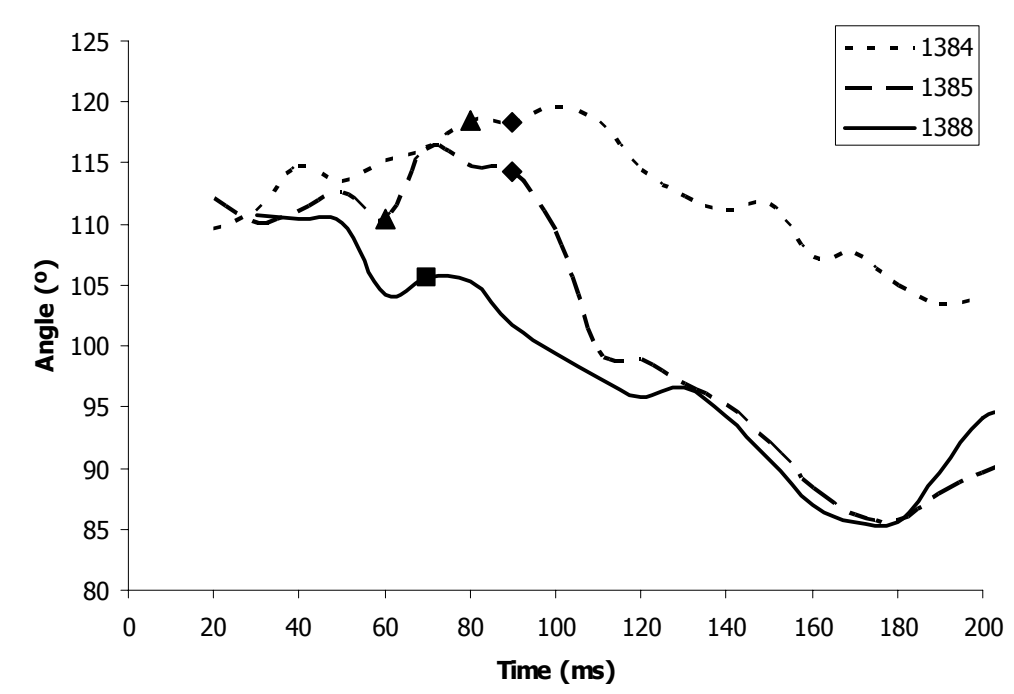

Fig. 4 - Torso angle vs. time. Maximum upper shoulder belt force is marked for each test with a diamond ( $\bullet$. Maximum lower shoulder belt force is indicated with a triangle $(\Delta)$. In test 1388, the maximum force happened at the samsojoge at both locations (ש).

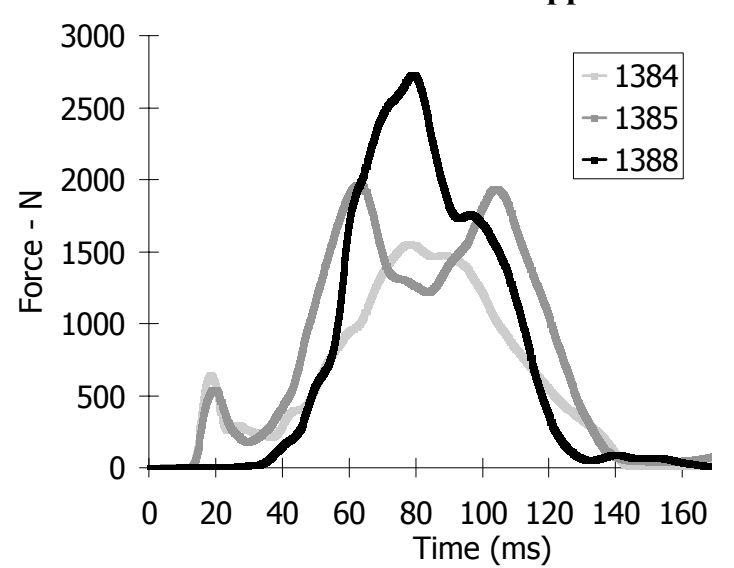

Fig. 5 - Lower shoulder belt tension

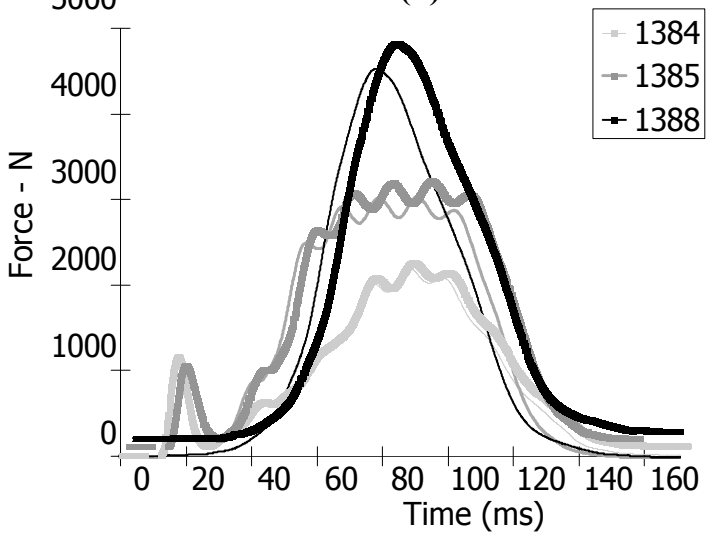

Fig. 6 - Upper shoulder belt tension

Thoracic deformation responses under the seatbelt load are included in Fig. 7. Contours of the deformed chest at the level of the $4^{\text {th }}$ (upper) and $8^{\text {th }}$ (lower) ribs at the time of maximum deflection of the torso are shown. In Test 1384, maximum force at the upper shoulder belt happened at $\mathrm{t}=88.1 \mathrm{~ms}$ which correlates with the maximum chest deformation at both locations ( $\mathrm{t}=90 \mathrm{~ms}$ and $\mathrm{t}=100 \mathrm{~ms}$, lower and upper respectively). In Test 1385 , the maximum torso deformation occurred at $\mathrm{t}=80 \mathrm{~ms}$, ahead of the maximum tension in the seatbelt $(\mathrm{t}=90.7$ $\mathrm{ms}$ ). This can be attributed to the force limiting characteristic of the restraint (force limiter yielding started approximately at $\mathrm{t}=68 \mathrm{~ms}$ ). Fig. 4 shows that the torso is already pitching forward and loading the belt at this time. In Test 1388, maximum belt force was found at $\mathrm{t}=79 \mathrm{~ms}$ and the maximum chest deformations occurred at $\mathrm{t}=80 \mathrm{~ms}$ and $\mathrm{t}=90 \mathrm{~ms}$ at the lower and upper location. As expected, chest deformation with the SB belt was higher than with the $\mathrm{PT}+\mathrm{FL}$ belt and resulted in a more localized deformation of the chest.

Maximum values of selected data channels are included in Table 4, together with the time at the event. History plots of the resultant accelerations at the head and vertebrae are presented in Fig. 9 to Fig. 13. Head resultant acceleration for the PT+FL belt exhibited a twopeak characteristic $(\mathrm{t}=62 \mathrm{~ms}$ and $\mathrm{t}=107 \mathrm{~ms})$ of value $60.5 \mathrm{~g}$. The first one corresponds to the onset of belt force limiting and the last to the end of the belt force limiting. In case of the ST belt, head acceleration presented a peak $(87.8 \mathrm{~g})$ at $\mathrm{t}=75 \mathrm{~ms}$ (corresponding to the maximum belt load). There is a spike in the acceleration time history in Test 1388 at $\mathrm{t}=99 \mathrm{~ms}$, due to direct contact of the wires of the instrumentation with the sensor array. 


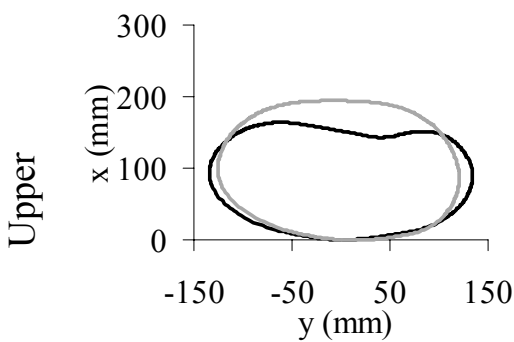

$\operatorname{Dmax}=50 \mathrm{~mm} ; \mathrm{t}=100 \mathrm{~ms}$

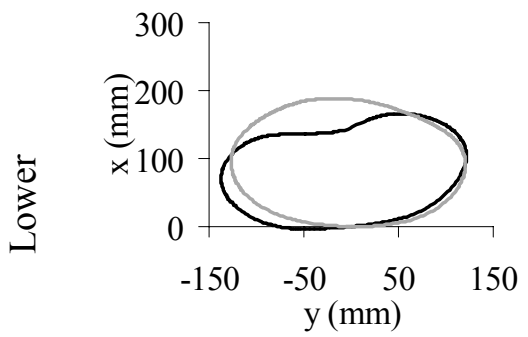

Dmax $=42 \mathrm{~mm} ; \mathrm{t}=90 \mathrm{~ms}$
1385

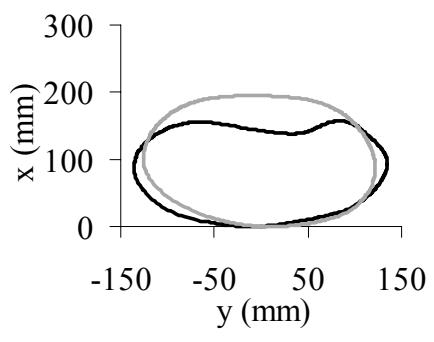

$\operatorname{Dmax}=59 \mathrm{~mm} ; \mathrm{t}=80 \mathrm{~ms}$

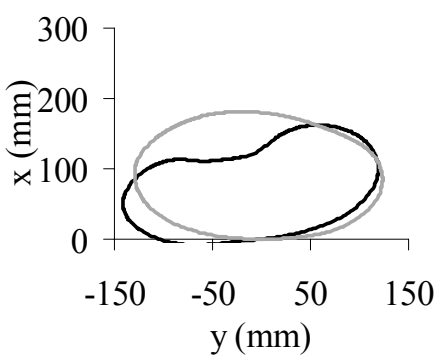

$\operatorname{Dmax}=52 \mathrm{~mm} ; \mathrm{t}=80 \mathrm{~ms}$
1388

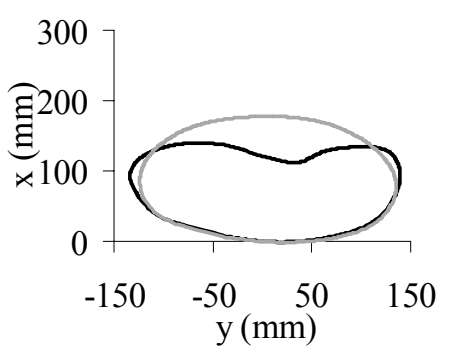

$\operatorname{Dmax}=63 \mathrm{~mm} ; \mathrm{t}=90 \mathrm{~ms}$

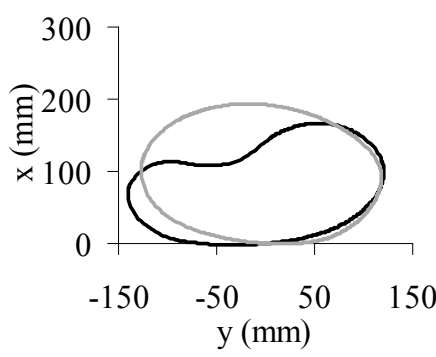

$\operatorname{Dmax}=60 \mathrm{~mm} ; \mathrm{t}=80 \mathrm{~ms}$

Fig. 7 - Chestband profiles at time of maximum chest deformation (Dmax).

Table 4 - Data summary of selected channels. Capital letters $(X, Y, Z)$ refer to the buck reference frame and lower case letters $(x, y, z)$ refer to the occupant reference frame.

\begin{tabular}{|c|c|c|c|c|c|c|c|c|c|}
\hline \multirow{2}{*}{\multicolumn{2}{|c|}{$\begin{array}{c}\text { Sensor Location, Source, } \\
\text { or Data Type }\end{array}$}} & \multirow[b]{2}{*}{ Axis $^{1}$} & \multirow[b]{2}{*}{ Unit } & \multirow{2}{*}{$\begin{array}{l}\text { Filter } \\
\text { Class }\end{array}$} & \multirow[b]{2}{*}{ Test } & \multicolumn{2}{|c|}{ Maximum } & \multicolumn{2}{|c|}{ Minimum } \\
\hline & & & & & & Value & $\begin{array}{l}\text { Time } \\
(\mathrm{ms})\end{array}$ & Value & $\begin{array}{l}\text { Time } \\
(\mathrm{ms})\end{array}$ \\
\hline \multirow{3}{*}{1} & \multirow{3}{*}{ Buck, Acceleration } & \multirow{3}{*}{$\mathrm{X}$} & \multirow{3}{*}{$\mathrm{g}$} & \multirow{3}{*}{ CFC 60} & 1384 & 13.8 & 74.8 & -1.10 & 168.9 \\
\hline & & & & & 1385 & 22.0 & 73 & -1.09 & 129.7 \\
\hline & & & & & 1388 & 22.6 & 71.6 & -0.99 & 149.3 \\
\hline \multirow{3}{*}{2} & \multirow{3}{*}{$\begin{array}{l}\text { Lower Shoulder } \\
\text { Belt, Force }\end{array}$} & \multirow{3}{*}{ na } & \multirow{3}{*}{$\mathrm{N}$} & \multirow{3}{*}{ CFC 60} & 1384 & 1555 & 78.1 & -- & -- \\
\hline & & & & & 1385 & 1965 & 62.9 & -- & -- \\
\hline & & & & & 1388 & 2730 & 79.2 & -- & -- \\
\hline \multirow{3}{*}{3} & \multirow{3}{*}{$\begin{array}{l}\text { Upper Shoulder } \\
\text { Belt, Force }\end{array}$} & \multirow{3}{*}{ na } & \multirow{3}{*}{$\mathrm{N}$} & \multirow{3}{*}{ CFC 60} & 1384 & 2203 & 88.1 & -- & -- \\
\hline & & & & & 1385 & 3035 & 90.7 & -- & -- \\
\hline & & & & & 1388 & 4528 & 78.1 & -- & -- \\
\hline \multirow{3}{*}{4} & \multirow{3}{*}{ Lap Belt, Force } & \multirow{3}{*}{ na } & \multirow{3}{*}{$\mathrm{N}$} & \multirow{3}{*}{ CFC 60} & 1384 & 996 & 77.9 & -- & -- \\
\hline & & & & & 1385 & 2671 & 65.5 & -- & -- \\
\hline & & & & & 1388 & 3469 & 69.9 & -- & -- \\
\hline \multirow{3}{*}{5} & & & & & 1384 & 29.3 & 69.8 & -- & -- \\
\hline & Acceleration & na & g & NA & 1385 & 61.6 & 106.5 & -- & -- \\
\hline & Resultant & & & & 1388 & 196.9 & 98.6 & -- & -- \\
\hline & & & & & 1384 & 54.3 & 18.5 & -- & -- \\
\hline 6 & T1, Acceleration & na & $\mathrm{g}$ & NA & 1385 & 40.6 & 102.6 & -- & -- \\
\hline & & & & & 1388 & 58.8 & 102.6 & -- & -- \\
\hline & & & & & 1384 & 21.8 & 89.8 & -- & -- \\
\hline 7 & 19, Acceleration & na & $\mathrm{g}$ & NA & 1385 & 45.3 & 79.4 & - & -- \\
\hline & & & & & 1388 & 82.8 & 80.5 & -- & -- \\
\hline & & & & & 1384 & 22.5 & 79.8 & -- & -- \\
\hline 8 & L4, Acceleration & na & $\mathrm{g}$ & NA & 1385 & 50.5 & 75.4 & -- & -- \\
\hline & & & & & 1388 & 68.1 & 76.9 & -- & -- \\
\hline & Pelvis, CG, & & & & 1384 & 21.3 & 82.2 & -- & -- \\
\hline 9 & Acceleration & na & $\mathrm{g}$ & NA & 1385 & 55.3 & 82 & -- & -- \\
\hline & Resultant & & & & 1388 & 68.4 & 81 & -- & -- \\
\hline & & & & & 1384 & 122.1 & 21.5 & -267.7 & 16.3 \\
\hline 10 & Sternum, & $x$ & g & $\begin{array}{l}\mathrm{CFC} \\
1000\end{array}$ & 1385 & 108.9 & 17.7 & -244.2 & 16.9 \\
\hline & & & & & 1388 & 33.2 & 67.2 & -70.1 & 63.5 \\
\hline
\end{tabular}



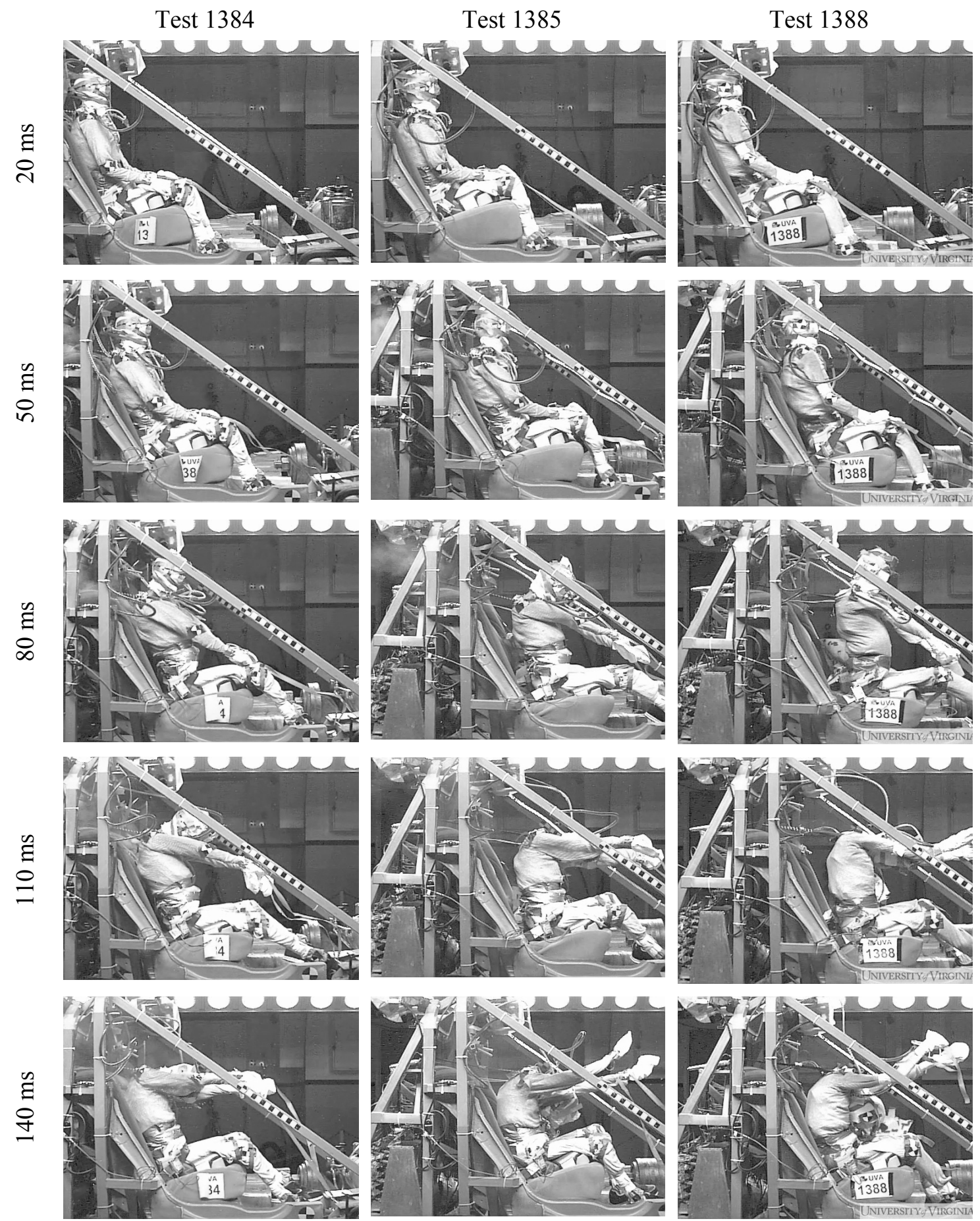

Fig. 8 - Images at different times during the impact showing the kinematics of the occupant.

The peak head acceleration was substantially greater with the SB system and the deceleration with this system expanded over a shorter period of time. The pretensioning effect on the acceleration time history of $\mathrm{T} 1$ is seen in Fig. 10 at time $\mathrm{t}=18 \mathrm{~ms}$, inducing an acceleration of 53g in Test 1384. Both 1385 and 1388 acceleration histories present a bimodel curve, but the peak acceleration values in case of the SB belt $(58.8 \mathrm{~g}$ and $52.1 \mathrm{~g})$ were higher than with the PT+FL belt (40.1 g and $32.9 \mathrm{~g})$. The valley in between the peaks in both cases corresponds to a decrease on lower shoulder belt force and lap belt force (being higher for the PT+FL $(2932 \mathrm{~N})$ than for the SB $(923 \mathrm{~N})$ ), allowing the pelvis to move forward and therefore diminishing the amount of rotation at T1 (see Fig. $8, \mathrm{t}=80 \mathrm{~ms}$ ). The initial effect of the pretension of the belt can be also observed in T9 and L4 traces (Fig. 11 and Fig. 12). 
Again, peak acceleration values with the PT $+\mathrm{FL}$ belt are lower than with the SB belt at these locations. Fig. 13 shows the resultant acceleration at the pelvis. The almost flat region corresponding to the maximum value of the acceleration (approximately between $\mathrm{t}=60 \mathrm{~ms}$ and $\mathrm{t}=90 \mathrm{~ms}$ ) is associated with the forward motion of the pelvis and the lower values of lap and lower shoulder belt forces.

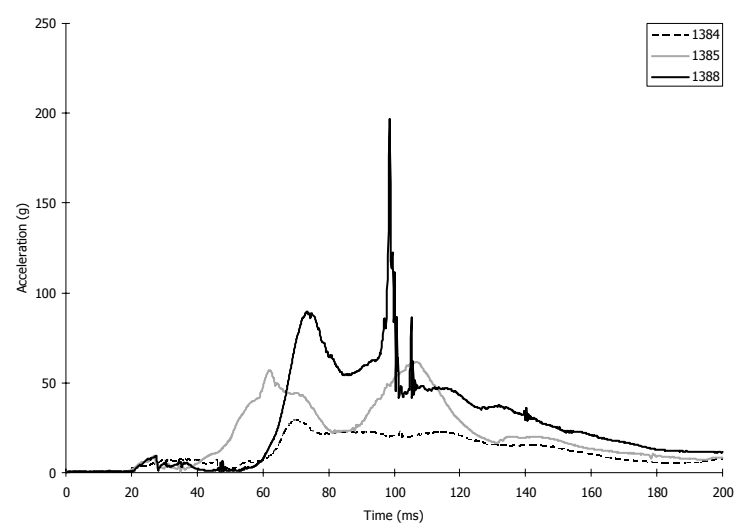

Fig. 9 - Head acceleration resultant

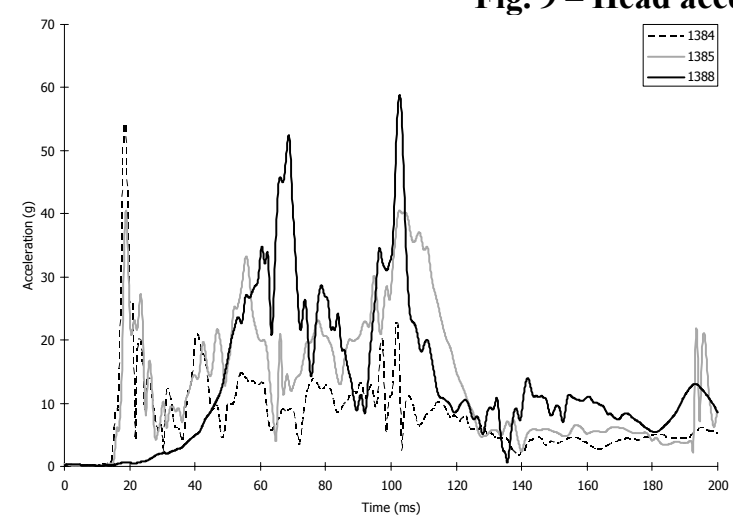

Fig. 10 - T1 acceleration resultant

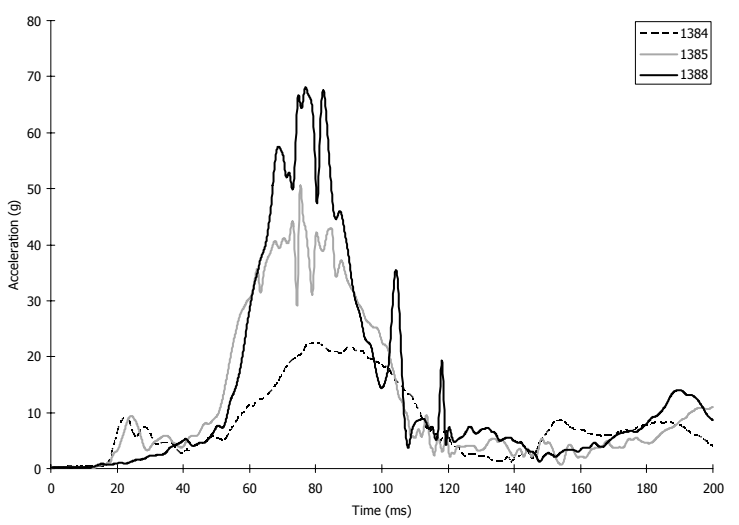

Fig. 12- Lower spine acceleration resultant

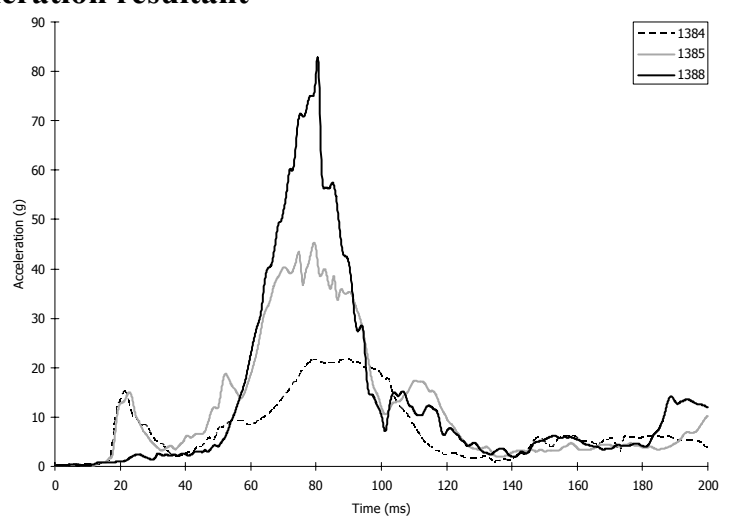

Fig. 11 - Mid spine acceleration resultant

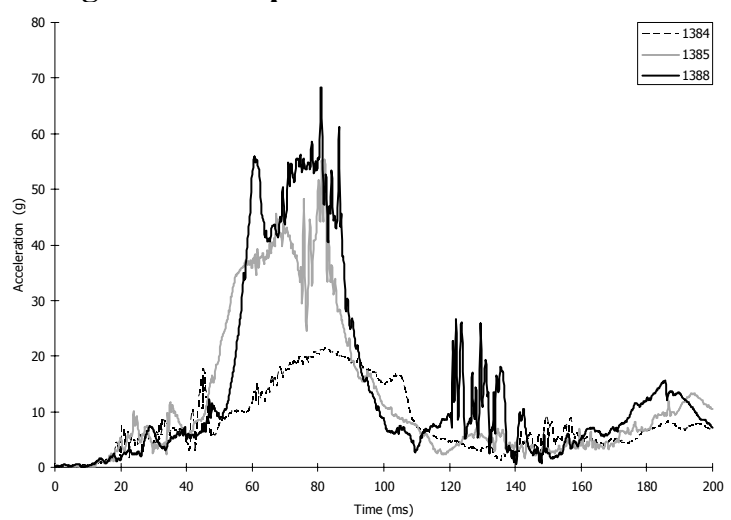

Fig. 13 - Pelvis acceleration resultant

\section{INJURY OUTCOME}

After Test 1384 a preliminary assessment of injuries through palpation was done. The mounts were still solidly attached and no evidence of injury was found. High-resolution (0.65-mm slice thickness) CT scans were performed after Test 1385 and Test 1388 and a detailed full-body necropsy was performed after test 1388. After Test 1385 (PT+FL) there was no injury to the cervical spine and no change in the existing T7 burst fracture but there were acute fractures of ribs on the left side of the rib cage (at the $1^{\text {st }}$ and $9^{\text {th }}$ levels). After Test 1388 , new acute rib fractures were observed in the CT scan (right: $2^{\text {nd }}, 5^{\text {th }}$; left: $3^{\text {rd }}, 4^{\text {th }}, 5^{\text {th }}$ ). The right clavicle was also fractured and an acute fracture of the left L4 superior articular facet was observed. The right distal tibia sustained a minimally displaced fracture and the 
right distal fibula presented a mildly comminuted fracture. The necropsy also revealed a partial tear of the interspinous and superspinous ligaments and a nearly complete tear of ligamentum flavum at the cervical spine The $\mathrm{C} 7$ facets were displaced superiorly (capsules remained intact). Fractures on the right transverse processes of C7, T1, T12 and L1 were also found. A summary of these injuries is presented in Table 5.

Table 5. Injury summary and correspondent AIS code for the injuries identified in the necropsy.

\begin{tabular}{|c|c|c|}
\hline Body Region & Injury & AIS Code \\
\hline Thorax & Greater than 3 fractured ribs on both sides without flail & $\begin{array}{c}450230.3(1998) \\
450203.3(2005)\end{array}$ \\
\hline Thorax & Right clavicle fracture & $752200.2(1998)$ \\
& Partial tear of superspinous ligament & 640284.1 \\
\hline Cervical Spine & Interspinous ligament partially disrupted & 640284.1 \\
\hline Cervical Spine & Near complete tear of ligamentum flavum & 640284.1 \\
\hline Cervical Spine & C7 right transverse process fracture & 650220.2 \\
\hline Cervical Spine & T1 right transverse process fracture & 650420.2 \\
\hline Spine & T9 spinous process fracture & 650418.2 \\
\hline Spine & T12 transverse process fracture & 650420.2 \\
\hline Spine & L1 transverse process fracture & 650620.2 \\
\hline Spine & &
\end{tabular}

\section{DISCUSSION}

Torso pitch and head excursion

Forman (2008) performed a series of ATD sled tests at nominal delta-v of $29 \mathrm{~km} / \mathrm{h}$ and 48 $\mathrm{km} / \mathrm{h}$ with the goal of comparing SB and PT $+\mathrm{FL}$ belts. The PT $+\mathrm{FL}$ belt resulted in less forward excursion of the pelvis and an increase in forward rotation of the torso. Also, the $\mathrm{PT}+\mathrm{FL}$ belt did not increase forward head excursion relative to the standard belt at $48 \mathrm{~km} / \mathrm{h}$ significantly. All tested dummy sizes (H3 6YO, H3 AF05, H3 AM50, THOR-NT) behave similarly. Bohman et al. (2006) showed that using PT+FL belt reduced the loading of the head, neck and chest in a series of tests with the Hybrid III 6 YO (using booster seats). The results of this study show similar results for a small PMHS. In this case, the initial pretension caused the torso to rotate backwards (increasing the lordosis of the spine) and the maximum forward rotation did not exceed that of the SB. This effect combined with the less forward excursion of the pelvis (probably caused again by the removal of belt slack by the pre-tensioner) results in a global reduction of head forward excursion.

Michaelson et al. (2008) in a series of PMHS tests in the rear seat observed forward torso pitch using standard seatbelts in every case. Forman et al. (2008) observed a higher torso pitch with the PT + FL belt than with the standard belt in ATDs. In these tests, both at low and high speed, the torso pitched initially backwards and then forwards when a PT+FL seatbelt was used. And consequently, the maximum forward pitch is not exceeded with the PT $+\mathrm{FL}$ seatbelt. This increase of the spinal lordosis can be seen in Fig. 8. This effect was not present in Forman et al. (2008) due to the rigidity of the ATD spine. Peak et al. (2006) reported that a pre-tensioner system provided earlier torso restraint and therefore limited torso forward motion. This may suggest that a small occupant can be more effectively restrained in the rear seat using a PT+FL seatbelt: the pretensioning will engage the torso earlier in the crash event (consequently, limiting forward head excursion) and the force provided by the belt will be enough to restraint the forward motion of the small occupant.

\section{Thoracic injuries}

The benefit of introducing a force limiting pre-tensioning seatbelt in conjunction with airbags to prevent thoracic injuries has been reported in the past (Miller, 1996). Its implementation in the rear seat has been also proposed time ago, though the concern about inducing extremely large forward head motion (Zellmer et al., 1998). Using a parametric MADYMO study, Kent et al. (2007) reported that there are likely different combinations of 
force-limiting and pre-tensioning belts that can decrease thoracic injury risk with no increase in forward head excursion (or with an acceptable one). Mertz and Dalmotas (2007) in an analysis of NASS data from 1988 to 2005 concluded that a $2.5 \mathrm{kN}$ shoulder belt load would reduce shoulder belt-induced AIS $\geq 3$ injuries in 99 percent of frontal collisions to adult occupants. Results from Test 1385 and Test 1388 support these studies.

Some concern can arise from the fact that repeated tests were conducted on the same subject. The tests presented here are part of a broader project conducted at the University of Virginia to assess the safety of the rear seat. Several other tests conducted with PMHS in this same environment showed that the $29 \mathrm{~km} / \mathrm{h}$ impact was almost non-injurious. Since the CT scan after the test at $48 \mathrm{~km} / \mathrm{h}$ using the FL+PT belt only showed two rib fractures, we decided to conduct one additional test with the ST belt to maximize the information obtained from this rare subject. Considering that only six pediatric PMHS have been tested in a booster seat to date, we believe that the information provided from these tests was relevant to advance our knowledge on pediatric response to frontal impacts (Kallieris et al., 1976).

\section{Neck injuries}

Smith (2005) proposed that force limiting seatbelts could prevent cervical and thoracic spine fractures in frontal impacts in medium to high delta-v impacts. Michaelson et al. (2008) suggested that a PT + FL belt could prevent lower neck injuries due to inertial loading of the neck. In this study, CT scans did not show any spinal fractures after the tests, but in the necropsy, several fractures were found at different cervical, thoracic and lumbar spine levels. Other soft tissue injuries and a displacement at the $\mathrm{C} 7$ facets were also observed. Fig. 8 shows the flexion of the neck at different times. The PT+FL belt prevented the neck from undergoing extreme flexion and hitting the chest in Test 1385 (see frame at $\mathrm{t}=140 \mathrm{~ms}$ ).

\section{CONCLUSIONS}

A series of three frontal impact sled tests was performed on a small child-like PMHS seated on a booster seat in the rear seat. Two different delta-v $(29 \mathrm{~km} / \mathrm{h}$ and $48 \mathrm{~km} / \mathrm{h})$ and two different restraint systems (SB belt and PT + FL belt) were used. The pre-tensioning force limiting seatbelt resulted in a more controlled kinematic response of the PMHS, reducing forward head and pelvis excursions without increasing torso pitch. A greater number of rib fractures and cervical spine injuries were observed after the test with the SB belt. These results suggest that the introduction of a pre-tensioning force limiting belt in the rear seat can be beneficial for small size occupants like children using booster seats.

\section{ACKNOWLEDGEMENTS}

The tests reported here were sponsored by Autoliv Research, who also supplied the restraint system components. The authors also acknowledge the National Highway Traffic Safety Administration for its support of UVA's rear-seat research program and, in particular, Steve Ridella and Shashi Kuppa for their technical insights. Ford Motor Company supplied equipment as well as technical input. Specifically, Stephen Rouhana and Priya Prasad deserve our thanks. Finally, the authors thank the institution Obra Social - Fundación "la Caixa" for their support in the form of an International Graduate Grant (FJ. Lopez-Valdes).

\section{References}

Adekoya, N., D. Thurman, D. White and K. Webb (2002). Surveillance for traumatic brain injury deaths--United States, 1989-1998. MMWR Surveill Summ. 51(10): 1-14.

Arbogast, K. B., I. Chen, D. Durbin and F. K. Winston (2004). Injury risks for children in child restraint systems in side impact crashes. IRCOBI Conference, Graz, Austria. 
Arbogast, K. B., R. A. Cornejo, M. J. Kallan, F. K. Winston and D. R. Durbin (2002). Injuries to children in forward-facing child restraints. Annu Proc Assoc Adv Automot Med 46: 213 30 .

Bohman K, Boström O, Olsson J, Haland Y. The effect of a pretensioner and a load limiter on a HIII $6 \mathrm{Y}$, seated on four different types of booster cushions in frontal impacts. IRCOBI Conference, Madrid, Spain. 2006.

Forman J, Michaelson J, Kent R, Kuppa S, Bostrom O. Occupant restraint in the rear seat: ATD responses to standard and pre-tensioning, force-limiting belt restraints. Annu.Proc.Assoc.Adv.Automot Med., 2008, 52, 141-154.

Kallieris D, Barz J, Schmidt G, Heess G, Mattern R. Comparison between child cadavers and child dummy by using child restraint systems in simulated collisions. Paper No. 760815. Society of Automotive Engineers, 1976.

Kent R, Forman J, Parent D, Kuppa S. Rear seat occupant protection in frontal crashes and its feasibility. $20^{\text {th }}$ Proceedings. International Technical Conference on the Enhanced Safety of Vehicles (ESV), Lyon, France, 2007.

Kuppa, S, Eppinger, R. (1998) Development of an Improved Thoracic Injury Criterion. Paper 983153, Society of Automotive Engineers.

Mertz HJ, Dalmotas DJ. Effects of shoulder belt limit forces on adult thoracic protection in frontal collisions. Stapp Car Crash J., 2007, 51, 361-380.

Michaelson J, Forman J, Kent R, Kuppa S. Rear seat occupant safety: kinematics and injury of PMHS restrained by a standard 3-point belt in frontal crashes. Stapp Car Crash J., 2008, 52, 295-325.

Miller HJ. Occupant performance with Constant Force Restraint Systems. Paper 960502, Society of Automotive Engineers, 1996.

National Highway Traffic Safety Administration. Federal Motor Vehicle Safety Standard 213: Child Restraint Systems. Washington DC, Code of Federal Regulations, 2001.

National Highway Traffic Safety Administration. Traffic Safety Facts. 2007 Data. Children. Available at www.nhtsa.gov.

Peak CI, Shaw CG, Crandall JR, Baek YH, Ko OS. Responses of Hybrid III $50^{\text {th }}$ and THORNT 50 ${ }^{\text {th }}$ in Sled Test with Different Seat Belt Pretensioner Configurations. IMECE200613551. ASME-IMECE-International Mechanical Engineering Congress and Exposition. 2006.

RBANDPC and DEFLECT User's Guide v.3.0. (2001). Conrad Technologies, Inc., Station Square One, Suite 102, Paoli Pennsylvania 19301.

Sherwood CP, Ferguson SA, Crandall JR. Factors leading to crash fatalitites to children in child restraints. Annu Proc Assoc Adv Automot Med 47, 2003:343-359.

Smith JA, Siegel JH, Siddiqi SQ, Spine and spinal cord injury in motor vehicle crashes: a function of change in velocity and energy dissipation on impact with respect to the direction of crash. J. Trauma. 2005;59:117-131.

Zellmer H, Lührs S, Brüggemann K. Optimized restraint systems for rear seat passengers. International Technical Conference on the Enhanced Safety of Vehicles (ESV), 1998, 316326. 